\title{
Determination of Genetic Similarities in Natural Populations of Drosophila melanogaster in Savanna Zone of Nigeria Using Microsatellite Markers
}

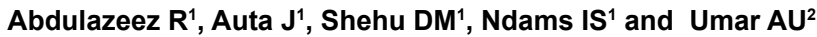

${ }^{1}$ Department of Biological Sciences, Ahmadu Bello University, Zaria, Nigeria

${ }^{2}$ National Animal Production Research Institute, Ahmadu Bello University, Shika, Zaria, Nigeria

\begin{abstract}
This study was carried out to determine genetic similarities in natural population of Drosophila melanogaster in savannah zone of Nigeria using microsatellite markers. A total of $184 \mathrm{D}$. melanogaster was collected using simple traps baited with banana and baker's yeast from Northern Guinea (Kaduna), Sudan (Kano) and Sahel (Azare). A total of 40 D. melanogaster were genotyped using 7 sets of microsatellite markers, the bands in the electrophoregramme were analysed and scored using the image Lab $^{T M}$. The result was used to compute dendrogramme based on Nei's genetic distance using MEGA 6. Result showed that studied population forms two (2) clusters at various degrees of similarities with Sudan savanna and Sahel Savanna forming a cluster at 0.21 then grouped with Northern Guinea Savanna to form the second $\left(2^{\text {nd }}\right)$ cluster at 0.78 distances, suggesting that Northern Guinea Savanna and Sudan Savanna Drosophila melanogaster populations have a recent common ancestor.
\end{abstract}

Keywords: Genetic similarities; Drosophila melanogaster; Microsatellite; Savannah zone; Nigeria

\section{Introduction}

Drosophila melanogaster [1] is generally known as fruit fly or vinegar fly. The fly is said to have probably originated from sub-Sahara Africa [2], but is also able to proliferate under temperate climate which could be as a result of the spread of beneficial mutations in non-Africa populations [3-6] and recent selection pressure imposed by man such as resistance to insecticides [7]. D. melanogaster serves as a multiple model organism as its embryo, larva, pupa and adult can be used as models in different toxicological settings. For instance, the embryo and the pupa can be used as models in developmental toxicological studies; the larva can be used to study physiological and behavioural processes, while the adult fly possess structures that can mimic the equivalent functions of mammalian reproductive tract, heart, kidney, gut and lung. [8-13]

Microsatellites were described by [5] as a series of very short (2-10 bp), middle repetitive, tandemly arranged, highly variable DNA sequences dispersed throughout living organisms genomes. Microsatellite marker gives a much higher estimate resolution even at small spatial scales when compared with other markers [12]. The objective of the study is to determine genetic similarities among $D$. melanogaster populations in savannah zone of Nigeria.

\section{Materials and Methods}

The fruit flies were collected from six different locations throughout the savannah zone. Males were directly identified to species before preserving in separate vials from the females containing $70 \%$ ethanol and stored at $-20^{\circ} \mathrm{C}$. Genomic DNA used as a template for PCR reaction was isolated from all samples using phenol-chloroform method as described by a conventional hot start PCR was done using seven sets of primers developed from Flybase and PRIMER 3 software. A $10 \mu \mathrm{L}$ PCR reaction was performed using $100 \mathrm{ng}$ of genomic DNA, $1.5 \mathrm{mM} \mathrm{MgCl}$, $200 \mu \mathrm{M}$ dNTPs, $1 \mu \mathrm{M}$ of each primer, 0.5 units Taq DNA polymerase. An initial denaturation at $96^{\circ} \mathrm{C}(5 \mathrm{~min})$, annealing at $53^{\circ} \mathrm{C}(1 \mathrm{~min})$ and extension at $72^{\circ} \mathrm{C}(5 \mathrm{~min})$ for 30 cycles.

PCR product was run on $1.5 \%$ agarose gel stained with ethidium bromide and visualized by Molecular Imager ${ }^{\circ} \mathrm{Gel} \operatorname{Doc}^{\mathrm{TM}} \mathrm{XR}+$ system with image $\mathrm{Lab}^{\mathrm{TM}}$ software of BIO-RAD calibrated to high sensitive level $(75 \%)$. The bands in the electrophoregramme were analysed and scored using image $\mathrm{Lab}^{\mathrm{TM}}$ and dendrogramme was established using MEGA 6 (Table 1).

\begin{tabular}{|c|c|c|c|c|}
\hline LOCUS & PRIMERS & BASE SIZE (bp) & $\begin{array}{l}\text { ANNEALING } \\
\text { TEMP. }\left({ }^{\circ} \mathrm{C}\right)\end{array}$ & GC \% \\
\hline DM18 & & 205 & $59.47,59.96$ & 45.00 \\
\hline $\mathrm{F}$ & GCCGGCCAAACTTAACAATA & & & \\
\hline $\mathrm{R}$ & GCCGGCCAAACTTAACAATA & & & \\
\hline DMPROSPER & & 201 & $60.01,60.05$ & 50.00 \\
\hline $\mathrm{F}$ & AGGCAAACAAAGGTGTGTCC & & & \\
\hline $\mathrm{R}$ & GGGAGGTCACTCATCTTGGA & & & \\
\hline Antp1 & & 199 & $59.99,59.93$ & 55.00 \\
\hline $\mathrm{F}$ & CAAGGACTTGCGTTCTCTCC & & & \\
\hline $\mathrm{R}$ & CACCTACGCGTTCGACTACA & & & \\
\hline DROACS2 & & 201 & $59.83,59.80$ & 50.00 \\
\hline $\mathrm{F}$ & TGTTTGGATGAGTCCAGCAG & & & \\
\hline $\mathrm{R}$ & ATCTCCACCTGGTACGGATG & & & \\
\hline DM30 & & 203 & $59.94,59.93$ & 45.00 \\
\hline $\mathrm{F}$ & TTTGGGTTTCTATCGCCAAC & & & \\
\hline $\mathrm{R}$ & AGGGAACTGTCCATGAATGC & & & \\
\hline DMWHITE & & 207 & $59.59,59.98$ & 45.00 \\
\hline $\mathrm{F}$ & GGTAAGCAGGGGAAAGTGTG & & & \\
\hline $\mathrm{R}$ & ATTTTTGTGGGTCGCAGTTC & & & \\
\hline DMtena & & 200 & 59.97 & 40.00 \\
\hline $\mathrm{F}$ & ACAATTTGCGTTGGGAAAAG & & & \\
\hline $\mathrm{R}$ & ACGGACAGGACCTCAATCAC & & & \\
\hline
\end{tabular}

Table 1: Drosophila melanogaster primers for genetic diversity assessment.

\section{Results and Discussion}

The dendrogramme (Figure 1) based on the 7 Microsatellite markers used on the basis of Nei's genetic distance indicated that studied

*Corresponding author: Abdulazeez R, Department of Biological Sciences Ahmadu Bello University, Zaria, Nigeria, Tel: +234(0)7033701917; E-mail queenrashdarling@gmail.com

Received October 07, 2016; Accepted October 17, 2016; Published October 24 2016

Citation: Abdulazeez R, Auta J, Shehu DM, Ndams IS, Umar AU (2016) Determination of Genetic Similarities in Natural Populations of Drosophila melanogaster in Savanna Zone of Nigeria Using Microsatellite Markers. Mol Biol 5: 177. doi:10.4172/2168-9547.1000177

Copyright: ( 2016 Abdulazeez R, et al. This is an open-access article distributed under the terms of the Creative Commons Attribution License, which permits unrestricted use, distribution, and reproduction in any medium, provided the original author and source are credited. 
Citation: Abdulazeez R, Auta J, Shehu DM, Ndams IS, Umar AU (2016) Determination of Genetic Similarities in Natural Populations of Drosophila melanogaster in Savanna Zone of Nigeria Using Microsatellite Markers. Mol Biol 5: 177. doi:10.4172/2168-9547.1000177

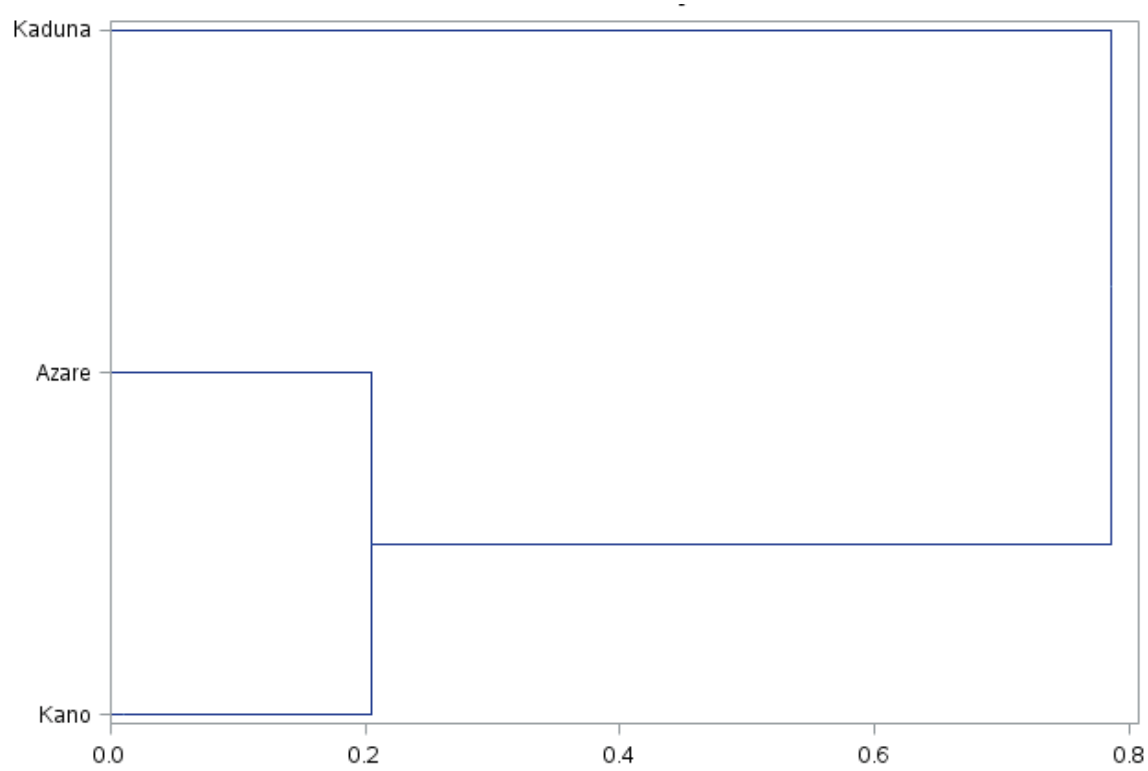

Figure 1: Dendrogramme representing phylogentic relationship of Drosophila melanogaster in Savanna zone of Nigeria. (Kaduna=Northern Guinea Savanna, Kano=Sudan Savanna, Azare=Sahel Savanna)

population forms two (2) clusters at various degree of similarities with Sudan savanna and Sahel Savanna forming a cluster at 0.21 , indicating a low level of genetic similarity. The first cluster then grouped with Northern Guinea Savanna to form the second $\left(2^{\text {nd }}\right)$ cluster at 0.78 distance showing a high genetic similarity among populations studied. The resulting clusters further support population subdivision in $D$. melanogaster. This is collaborated by several other studies $[4,11,12]$.

Conclusively, consistent cluster formed between the populations which quantified the degree of relationships between $D$. melanogaster in the various vegetation zones with Northern Guinea Savanna closely related to Sudan Savanna.

\section{References}

1. Meigen JW (1830) Systematische Beschreibung der bekannten europäischen zweiflügeligen Insekten. Schulz-Wundermann.

2. Capy P, Gibert P, Boussy I (eds.) (2004) Preface. In: Drosophila melanogaster, Drosophila simulans: So similar, so different. Contemporary issues in genetic and evolution. Kluwer Academic Publishers, The Nertherlands, pp: 1-3.

3. Kauer M, Zangerl B, Dieringer D, Schlotterer C (2003) Chromosomal patterns of microsatellite variability contrast sharply in African and non-African populations of Drosophila melanogaster. Genetics 160: 247-256.

4. Hale LR, Singh RS (1987) Mitochondrial DNA variation and genetic structure in populations of Drosophila melanogaster. Molecular Biology Evolution 4 : 622-637.

5. Kahl G (2001) The dictionary of gene technology. Wiley-VCH, Weinheim.

6. Kirby DA, Stephan W (1996) Multi-locus selection and the structure of variation at the white gene of Drosophila melanogaster. Genetics 144: 635-645.

7. Daborn P, Boundy S, Yen J, Pittendrigh B, Ffrench R (2001) DDT Resistance in drosophila correlates with Cyp6g1 over-expression and confers crossresistance to the neonicotinoid imidacloprid. Molecular Genetics Genomics 266: 556-563.

8. Andretic R, Kim YC, Jones FS, Han KA, Greenspan RJ (2008) Drosophila D1 dopamine receptor mediates caffeine-induced arousal. Proceedings of the National Academy of Sciences, USA 105: 20392-20397.

9. Nichols CD, Rones J, Prat W, Sanders-Bush E (2002) Hallucinogens and drosophila: Linking serotonin receptor activation to behaviour. Neuroscience 115: 979-984.

10. Schlotterer C, Vogl C, Tautz D (1997) Polymorphism and locus-specific effects on polymorphism at microsatellite loci in natural Drosophila melanogaster populations. Genetics 146: 309-320.

11. Schlotterer C, Neumeiern H, Sousa C, Nolte V (2005) Highly structured Asian Drosophila melanogaster populations: A new tool for hitchhiking mapping? Genetics Society of America 172: 287-292.

12. Turlure $C$, Vandewoestijne S, Baguette $M$ (2014) Conservation genetics of threatened butterfly: Comparison of allozymes, RAPDs and microsatellites. BMC Genetics 15: 114-125.

13. Wolf FW, Herbelein $U(2003)$ Invertebrate models of drug abuse. Journal of Neurobiology 54: 161-178. 